\title{
Estudo da viabilidade do enxerto de ovário na bolsa omental de ratos utilizando Ciclosporina A.
}

\author{
Study about the feasibility of ovarian graft in rats’ omentum pouch, using \\ cyclosporine A.
}

\author{
Nara Macedo Botelho Brito ${ }^{2}$, Inêz Ohashi Torres ${ }^{3}$, Edvaldo Lima Silveira ${ }^{4}$, Lorena Lira Tavares dos Santos ${ }^{3}$ \\ 1. Trabalho realizado no Laboratório de Cirurgia Experimental (LCE) e Laboratório de Bioquímica do Centrode Ciências \\ Biológicas e da Saúde (CCBS) da Universidade do Estado do Pará (UEPA) com apoio financeiro do Programa de \\ Iniciação Científica da Pró-Reitoria de Pesquisa e Pós-Graduação (PROPESP)/UEPA. \\ 2. Professora Adjunto da Universidade do Estado do Pará. \\ 3. Graduandos do Curso de Medicina da UEPA. Estagiários do LCE - UEPA \\ 4. Professor Assistente 4 da Universidade do Estado do Pará.
}

\section{RESUMO}

Objetivo: Estudo comparativo do enxerto autólogo e heterólogo de ovário na bolsa omental de ratas, utilizando ciclosporina A. Métodos: No presente estudo, foram utilizadas 20 ratas distribuídas randomicamente em quatro grupos, denominados grupo controle (animais submetidos à ooforectomia); grupo A (enxerto autólogo de ovário); grupo H (enxerto heterólogo de ovário); e grupo C (enxerto heterólogo de ovário e tratamento com ciclosporina A). Todos os animais foram submetidos à ooforectomia bilateral. Um dos ovários removidos foi individualizado e enxertado no omento maior do animal. Os animais do grupo C receberam a dose de $10 \mathrm{mg} / \mathrm{kg} /$ dia de ciclosporina por via subcutânea durante todo o período do experimento. Após um período de 33 dias, todos os animais foram submetidos a uma nova intervenção cirúrgica para identificação do leito receptor e retirada do ovário transplantado, além do útero e da vagina, seguido de eutanásia. As peças foram submetidas a processamento histológico e coloras pela hematoxilina eosina. Resultados: Todos os grupos apresentaram epitélios vaginal e uterino com 1 a 2 fileiras de células cúbicas ou cilíndricas simples, núcleo arredondado e central. Houve também grande reação inflamatória em todo o enxerto, com áreas de necrose. Ocorreu óbito de um animal do grupo C no $20^{\circ}$ dia do experimento. Conclusão: Conclui-se que o enxerto de ovário íntegro realizado em omento maior de ratas nesta amostra, independente do uso da Ciclosporina, não mostrou-se viável.

Descritores: Sobrevivência de Enxerto. Ovário. Bolsa Omental. Ciclosporina. Ratos.

\begin{abstract}
Purpose: To study comparatively ovarian autograft and heterograft in rats' omentum pouch, using Cyclosporine A. Methods: In the present study 20 rats, distributed equally in four groups, had been used: Control Group (rats submitted to ooforectomy); Group A (ovarian autograft); group H (ovarian heterograft); e group C (ovarian heterograft and treatment with Cyclosporine A). All animals had been submitted to a bilateral ooforectomy. One of the removed ovaries had been individualized and grafted in Greater Omentum. The animals from group C received 10mg/kg/dia of cyclosporine subcutaneously during the period of the experiment. All animals had been submitted to a new surgical intervention after a period of 33 days for identification of the receiving bedstead and withdrawal of the grafted ovary, beyond the uterus and the vagina, followed of euthanasia. The parts had been submitted to the histological process of routine. Results: All groups presented vaginal and uterine epithelium with one or two rows of simple cubical or cylindrical cells, spherical and central nucleus. It also had great inflammatory reaction in all grafts, with necrosis areas. At the $20^{\text {th }}$ day of the experiment, one of the animals of group $\mathrm{C}$ died. Conclusion: It was concluded that the graft of the entire ovary in Greater Omentum of rats in this sample, independently of the use of Cyclosporine, did not revealed viable.
\end{abstract}

Key words: Graft. Ovary. Survival Peritoneal Cavity. Cyclosporine. Rats.

\section{Introdução}

O implante ovariano preserva a função deste órgão e minimiza os efeitos indesejáveis do climatério precoce em mulheres ooforectomizadas ${ }^{1}$. Isto se deve ao fato de que o ovário de mamíferos, quando transplantado para um sítio ectópico, torna-se hormonalmente competente e capaz de ovular dentro de poucas semanas ${ }^{2}$. No entanto, problemas técnicos dos transplantes, como a incerteza do sucesso da revascularização do órgão, a rejeição do tecido transplantado e a toxicidade das drogas imunossupressoras, freqüentemente obscurecem o objetivo original desse tópico ${ }^{3}$. Vários estudos experimentais estão sendo realizados com o objetivo de se conhecer a técnica operatória 
mais adequada para a realização do enxerto ${ }^{4,5,6,7}$. Como exemplo, podem-se citar estudos realizados na região subperitonial de ratas, que apresentou eficácia de $50 \%{ }^{6}$ e na região subcutânea geniana de hamster, o qual apresentou $53,3 \%{ }^{7}$. O enxerto autólogo de ovário fragmentado no omento maior de ratos mostrou-se também bastante viável. ${ }^{8}$ Experimentos realizados com enxerto de baço neste mesmo sítio, mostraram que há maior integração e melhor desenvolvimento do órgão transplantado, comparando-se os dados aos resultados obtidos com enxertos de baço na tela sub-cutânea de ratos. Isto ocorre provavelmente devido ao estabelecimento de melhor irrigação do tecido, ocorrendo então diminuição da necrose e da fibrose. ${ }^{9}$ Uma alternativa a ser estudada é a administração de ciclosporina A, um decapeptídeo de origem fúngica, que, usada como droga imunossupressora, permitiu o renascimento dos transplantes de coração, fígado e pulmão, uma vez que não causa mielossupressão. A ciclosporina A age nos linfócitos $\mathrm{T}$ auxiliares (Th) e linfócitos T citotóxico (Tc), inibindo a produção de citocinas, como a IL-2. Dentre seus efeitos colaterais, destacam-se: hipertensão arterial, nefro, neuro e hepatotoxicidade.

Existem numerosas afecções que levam ao estabelecimento de perda da função ovariana, como casos de pacientes do sexo feminino com câncer submetidas à quimioterapia e/ou radioterapia, que estão em risco de sofrer menopausa, associada a efeitos adversos na saúde em geral. Dentre as alternativas para restaurar função ovariana, o enxerto de ovário tem sido considerado a mais fisiológica ${ }^{1}$. Devido à grande contribuição que o estudo de tal procedimento pode trazer para o aprimoramento das técnicas de enxerto, este trabalho se propõe a analisar experimentalmente o enxerto heterólogo de ovário na bolsa omental de ratas tratando-as com ciclosporina A.

\section{Objetivo}

Estudar comparativamente o enxerto autólogo e heterólogo de ovário na bolsa omental de ratas, utilizando ciclosporina A.

\section{Métodos}

\section{Amostra}

No presente estudo, foram utilizados 20 ratos ( Rattus norvegicus albinus ), da linhagem Wistar, fêmeas, virgens, adultos, pesando entre 250-300 gramas, provenientes do biotério do instituto Evandro Chagas ( Belém-Pará ), adaptados ao Laboratório de Cirurgia Experimental (LCE) da Universidade do Estado do Pará (UEPA) por 15 dias antes do início do experimento, mantidos em ambiente controlado, com água e ração ad libitum. Os animais foram distribuídos por randomização em quatro grupos de estudo, os quais foram denominados grupo controle, cujos animais foram submetidos à ooforectomia; grupo A, no qual os animais foram submetidos à ooforectomia e enxerto autólogo de ovário; grupo $\mathrm{H}$, no qual os animais foram submetidos à ooforectomia e enxerto heterólogo de ovário; e grupo C, no qual os animais foram submetidos à ooforectomia, enxerto heterólogo de ovário e tratamento com ciclosporina $\mathrm{A}$.

\section{Procedimentos}

Todos os animais, sob anestesia inalatória de éter etílico, foram submetidos à ooforectomia bilateral, através de incisão abdominal xifo-púbica, identificação de ambos os ovários, ressecção de cada ovário incluindo o terço proximal do corno uterino e síntese de corno uterino com um nó simples com fio de náilon monofilamentado 3-0.

Imediatamente após a ooforectomia nos animais, no mesmo ato operatório, um dos ovários removidos foi individualizado do fragmento de corno uterino e mantido em soro fisiológico em temperatura ambiente durante a confecção do leito para recebimento do enxerto no omento maior do animal. A técnica consistiu no implante do ovário íntegro no omento maior por sutura omento-omental envolvente, com pontos separados de mononylon 4-0 simples. Os animais do grupo $\mathrm{C}$ receberam após a intervenção cirúrgica a dose de $10 \mathrm{mg} / \mathrm{kg} /$ dia de ciclosporina por via subcutânea durante todo o período do experimento.

Todos os animais foram submetidos a uma nova intervenção cirúrgica, após um período de 33 dias, para identificação do leito receptor e retirada do ovário transplantado, além do útero e da vagina.

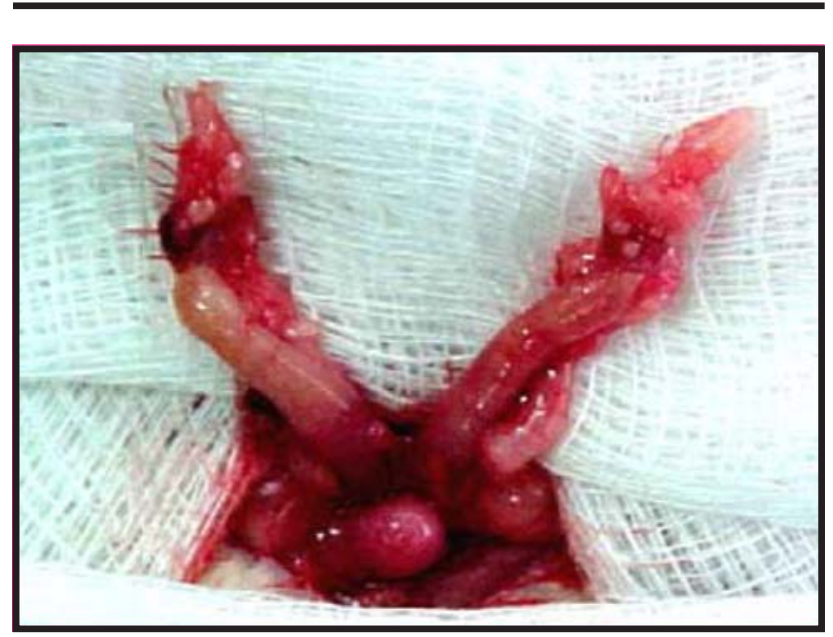

FIGURA 1 - Exposição dos ovários, útero e bexiga.

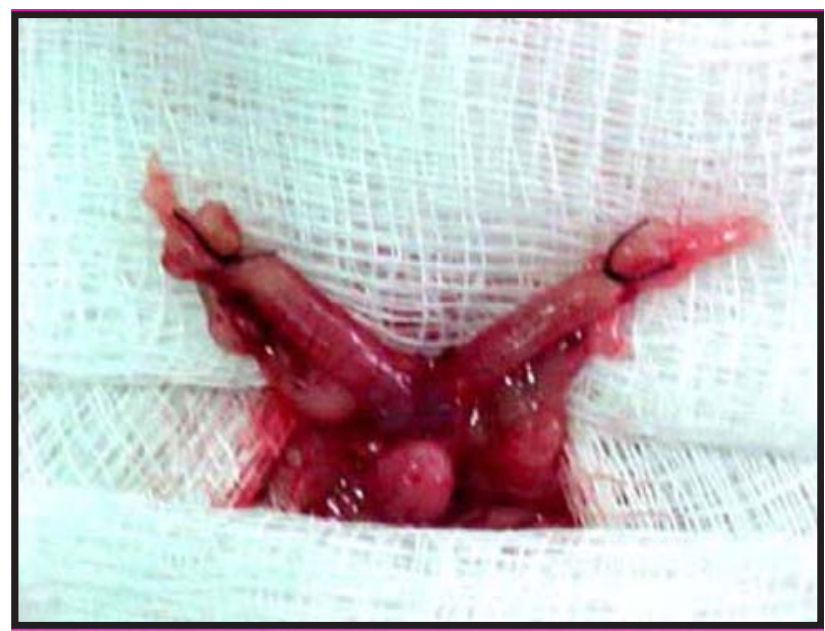

FIGURA 2 - Ooforectomia bilateral. 


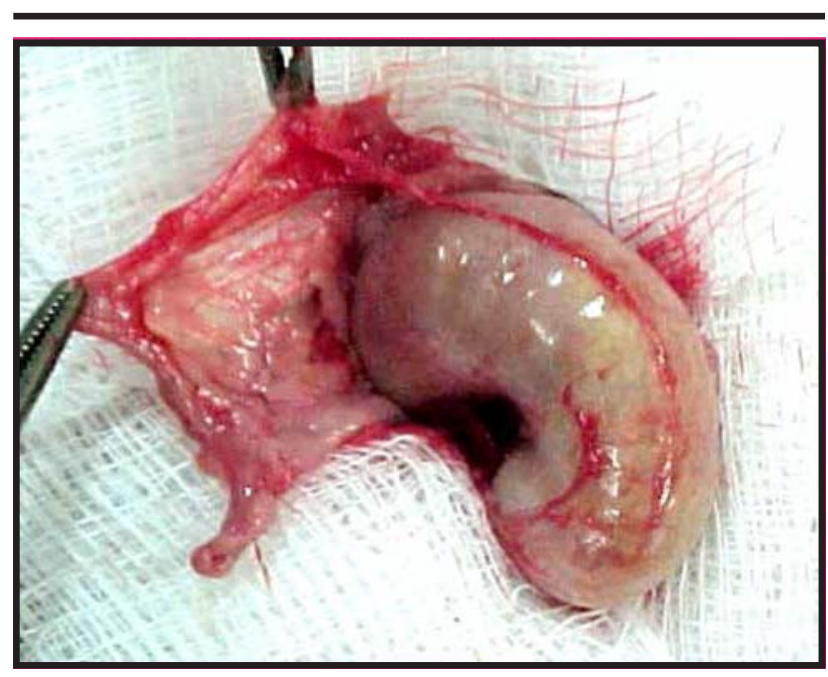

FIGURA 3 - Preparação do Omento Maior para recebimento do enxerto.

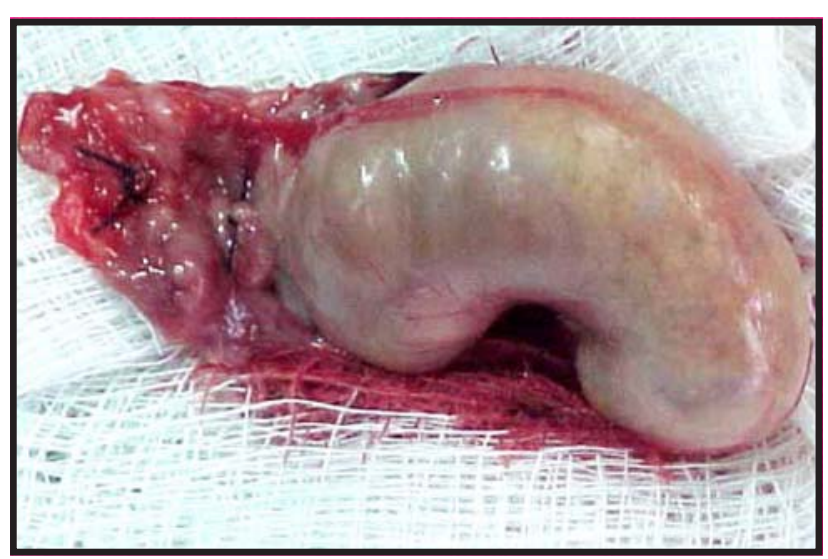

FIGURA 4 - Bolsa omental.

As peças foram fixadas em formol a $10 \%$ por sete dias, após o qual foram submetidos a processamento histológico de rotina. Os cortes foram obtidos em micrótomo ajustado para 5 micrômetros, corados pela Hematoxilina-eosina e analisados ao microscópio óptico.

Todos os animais foram submetidos à eutanásia com dose letal de éter etílico ao final do experimento.

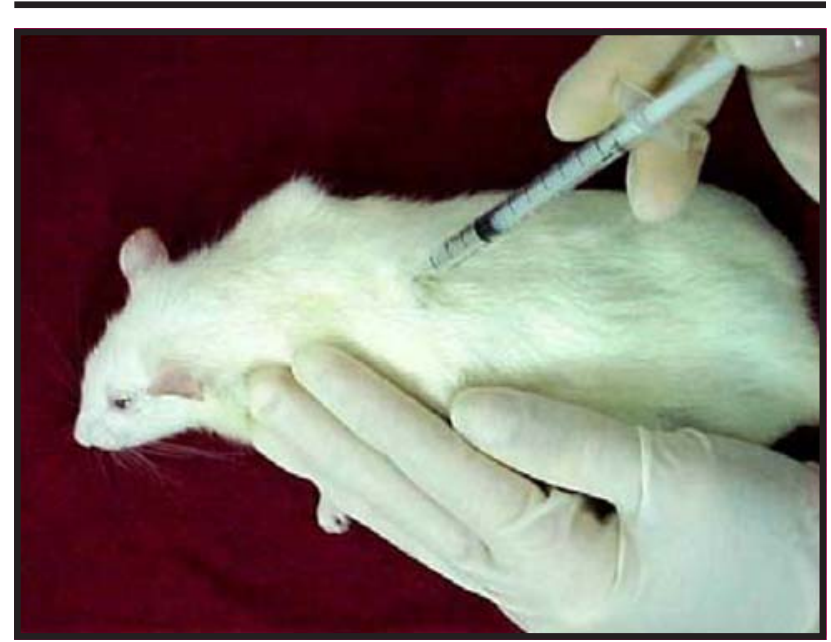

FIGURA 5 - Administração de Ciclosporina A.

\section{Resultados}

Todos os grupos do experimento apresentaram epitélios vaginal e uterino com 1 a 2 fileiras de células cúbicas ou cilíndricas simples, núcleo arredondado e central. Nos grupos A, H e C houve grande reação inflamatória envolvendo o omento maior e o enxerto, com áreas de necrose ou hialinização. Houve óbito de um animal do grupo $\mathrm{C}$ no $20^{\circ}$ dia do experimento.

TABELA 1 - Características histológicas do ovário no grupo enxerto autólogo de ovário em ratas.

\begin{tabular}{llll}
\hline & Presença & Ausência & Total \\
\hline Folículos & 0 & 5 & 5 \\
Cistos foliculares & 2 & 3 & 5 \\
Corpo Lúteo & 0 & 5 & 5 \\
Necrose & 2 & 3 & 5 \\
Vasos Congestos & 5 & 0 & 5 \\
Fibrose & 2 & 1 & 5 \\
\hline
\end{tabular}

FONTE: Protocolo histológico do trabalho.

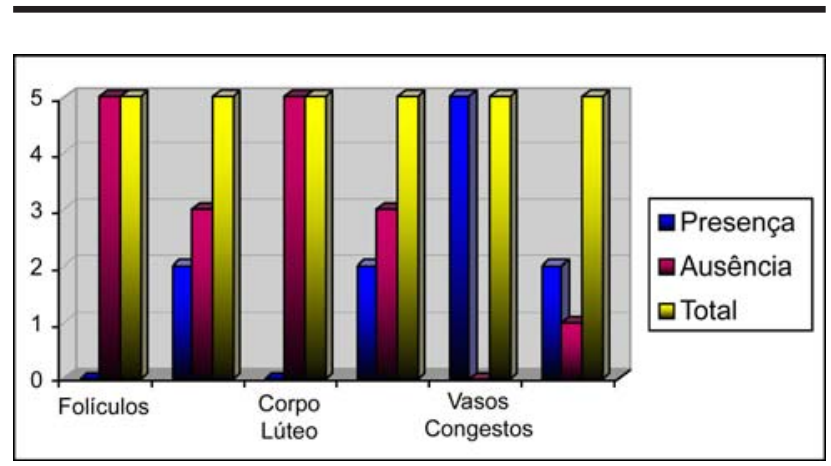

FIGURA 1 - Características histológicas do ovário no grupo enxerto autólogo de ovário.

TABELA 2 - Características histológicas do ovário no grupo enxerto heterólogo de ovário em ratas.

\begin{tabular}{llll}
\hline & Presença & Ausência & Total \\
\hline Folículos & 0 & 5 & 5 \\
Cistos foliculares & 2 & 3 & 5 \\
Corpo Lúteo & 0 & 5 & 5 \\
Necrose & 1 & 4 & 5 \\
Vasos Congestos & 5 & 0 & 5 \\
Fibrose & 4 & 1 & 5 \\
\hline
\end{tabular}

FONTE: Protocolo histológico do trabalho. 


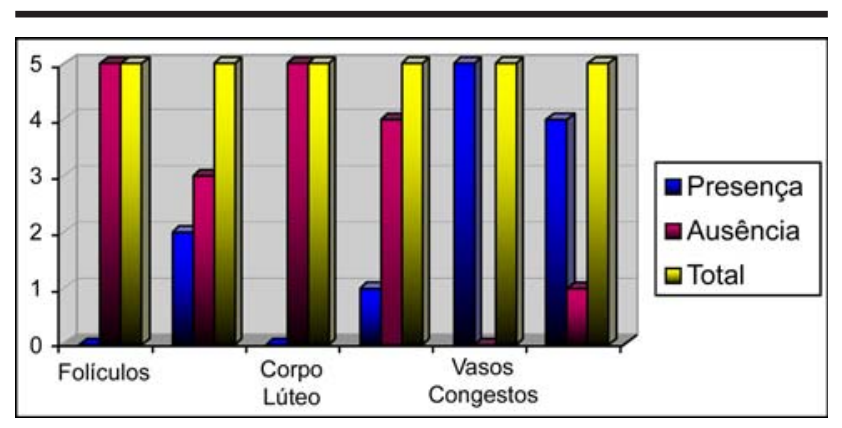

FIGURA 2 - Características histológicas do ovário no grupo enxerto heterólogo de ovário.

TABELA 3 - Características histológicas do ovário no grupo enxerto heterólogo de ovário em ratas, associado ao tratamento com Ciclosporina A.

\begin{tabular}{llll}
\hline & Presença & Ausência & Total \\
\hline Folículos & 0 & 4 & 4 \\
Cistos foliculares & 2 & 2 & 4 \\
Corpo Lúteo & 0 & 4 & 4 \\
Necrose & 1 & 3 & 4 \\
Vasos Congestos & 1 & 3 & 4 \\
Fibrose & 3 & 1 & 4 \\
\hline
\end{tabular}

FONTE: Protocolo histológico

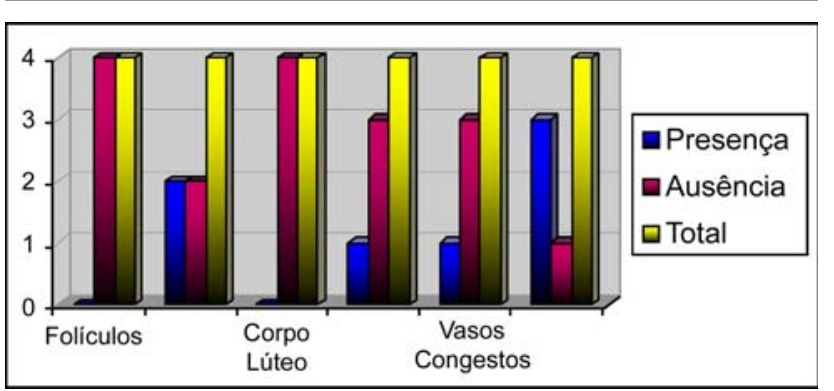

FIGURA 3 - Características histológicas do ovário no grupo enxerto heterólogo de ovárioassociado ao tratamento com Ciclosporina A.

\section{Discussão}

Infertilidade e menopausa precoce podem ser emocional e fisicamente devastadores.

Com a realização da histerectomia e outros procedimentos pélvicos, muitas vezes os ovários são retirados, o que promove insuficiência hormonal que pode evoluir, em médio prazo, com osteoporose e outras complicações sistêmicas. ${ }^{8}$ Nestes casos, o transplante, autólogo ou heterólogo de ovário, corresponde a uma alternativa viável para a restauração da função ovariana. No entanto, um dos principais contratempos para o sucesso deste procedimento é a vascularização inadequada do órgão, que leva à isquemia e necrose de grande parte do tecido enxertado. Baseado nisso, afirmou-se por algum tempo que a maior ênfase das pesquisas deveriam ser em torno das anastomoses microvasculares e suas implicações. ${ }^{3}$

Contudo, trabalhos posteriores notaram que alguns ovários apresentavam anexos vasculares já em torno de 24 horas após o transplante, e que após 48 horas, apresentavam-se profusamente revascularizados, sugerindo que a neovascularização é ativa e agudamente promovida pelo próprio órgão enxertado, mesmo na ausência das anastomoses microvasculares.

Estes resultados sugerem também, que o aumento da secreção das gonadotrofinas, contribui para a revascularização do enxerto de ovário, regulando a expressão gênica dos dois maiores fatores angiogênicos (Fator de Crescimento Endotelial Vascular e Fator de Crescimento Transformante â ). Apesar do grande estímulo a angiogênese levar a uma revascularização precoce do órgão, enfrenta-se ainda outras dificuldades, como a reação inflamatória que pode ocorrer, mesmo nos transplantes autólogos, provocando perda importante de tecido e funcionalidade do órgão. Visando diminuir este problema, foi feito o uso de um potente imussupresor: a ciclosporina A, que não obteve sucesso neste trabalho, comparando-se o grupo $\mathrm{C}$ aos grupos que não a receberam, o que levou a pensar inicialmente que o motivo que inviabilizou o enxerto não seria de origem imunológica e sim isquêmica. Porém, com a análise microscópica, notou-se presença de grande quantidade de células inflamatórias, principalmente polimorfonucleares, tanto no enxerto quanto no omento maior subjacente das ratas em todos os grupos. Observouse, além de intensa reação inflamatória, presença de necrose tecidual, hialinização e vasos congestos nos tecidos enxertados, suscitando a possibilidade de imunossupressão inadequada, talvez pelo volume de Ciclosporina utilizado ter sido insuficiente.

Apesar dessa imunossupressão ineficiente, ocorreu óbito de um dos animais do grupo Ciclosporina no $14^{\circ}$ dia de pós-operatório, possivelmente pelo efeito tóxico da Ciclosporina A ou pela grande suscetibilidade a infecções que o animal imunossuprimido apresenta. Pesquisas mostraram que a ciclosporina A apresenta ações deletérias em ratas ooforectomizadas, exacerbando os efeitos da ooforectomia: acelerando o alto índice de osteopenia associado à deficiência de estrogênio e levando a um aumento da glicose sanguínea. Neste caso foi estudada a dose de Ciclosporina A de $15 \mathrm{mg} / \mathrm{kg}$ e notou-se efeito protetor com a administração de Raloxifene (composto semelhante ao estrogênio) ${ }^{13}$. Esperava-se no presente estudo que o enxerto também exercesse uma função protetora em relação ao metabolismo das ratas, no entanto, notou-se que os efeitos tóxicos da Ciclosporina e a vulnerabilidade devido à imunossupressão permaneceram elevados, levando ao óbito de um dos animais do grupo Ciclosporina, mesmo com a utilização de dose mais baixa da droga (10mg/kg).

Contudo, estudos com coelhos, chegaram à conclusão de que o transplante tubo-ovariano heterólogo é viável nesses animais, e que a Ciclosporina A melhora não apenas a viabilidade da tuba uterina, mas também a função ovariana após o tranplante, permitindo que ocorresse prenhes em $38 \%$ das ratas do grupo que recebeu ciclosporina A, que é um percentual elevado, principalmente comparando-se ao grupo que não recebeu a droga, o qual não apresentou nenhuma prenhes. ${ }^{14}$ Essa ação benéfica da Ciclosporina no enxerto, pode ser melhor entendida com a pesquisa a respeito da ação da Ciclosporina A sobre a função ovariana, 
a qual concluiu que há uma repercussão direta da Ciclosporina sobre os níveis das gonadotrofinas. Notouse, que ocorre um aumento de Hormônio luteinizante e Hormônio folículo estimulante, a partir do segundo dia de admnistração da Ciclosporina, mesmo em animais que mantém seus ovários intactos. ${ }^{15}$ Com isso, além da proteção do enxerto, evitando-se o processo inflamatório, haveria também um maior estímulo à neo-formação vascular, devido ao aumento do nível sérico das gonadotrofinas, que como foi visto, pode ter ação estimulante sobre a revascularização do órgão enxertado.

Apesar dessa ação favorável da Ciclosporina A em relação ao enxerto, no trabalho realizado a partir do transplante tubo-ovarino em coelhos, ocorreu óbito de 36\% dos animais do grupo que recebeu a droga, portanto, os efeitos deletérios da drogas foram bastante elevados, praticamente equiparando-se ao número de animais que obtiveram sucesso com o procedimento. Desse modo, é importante que as pesquisas futuras baseiem-se em medicações menos tóxicas, talvez antiinflamatórios alternativos como certas plantas medicinais de uso popular, por exemplo, a Copaíba, que além de efeito antiinflamatório, mostrou ter efeito estrogênico com aplicação tópica em vagina de ratas ${ }^{12}$. O percentual de ratas com ciclo estral normal após o enxerto varia também em função do sítio de implantação do enxerto. Cerca de $50 \%$ dos enxertos autólogos de ovário íntegro realizados no espaço subperitoneal mostram-se viáveis, com desenvolvimento da foliculogênese compatível com a normalidade. ${ }^{6}$

Um estudo comparativo, realizado com o enxerto de ovário íntegro ou fragmentado no omento maior, notou que apenas $13 \%$ das ratas que receberam enxerto de ovário íntegro apresentaram ciclo (completo ou incompleto) três meses após o procedimento. Enquanto o enxerto de ovário fragmentado alcançou resultados significativamente melhores, chegando a 53\% de ratas com ciclo completo ou incompleto três meses após o implante autólogo de ovário fatiado. Isto ocorre porque a fragmentação do órgão enxertado em omento maior evita o inconveniente processo isquêmico que ocorre no transplante do ovário íntegro. ${ }^{9}$

Com a percentagem de ratas em estro no grupo que recebeu enxerto íntegro de ovário (13\%), nota-se a possibilidade de que o número de ratas utilizadas no presente estudo tenha sido insuficiente, devendo-se estender o número de animais dos grupos que receberam enxerto autólogo ou heterólogo de ovário para no mínimo 15 ratas. O fato de que o atual trabalho valeu-se da mesma técnica utilizada no enxerto de ovário subperitoneal em ratas (eficácia de 50\%), mas não obteve o mesmo sucesso, indica que possivelmente o espaço subperitoneal seja um local mais adequado para a enxertia do ovário, quando comparado ao omento maior.

Este dado, não está de acordo com a pesquisa feita através do enxerto autólogo de baço no omento maior e na tela sub-cutânea de ratas, que resultou em melhor desenvolvimento do órgão transplantado no omento maior, havendo maior integração e melhor desenvolvimento do órgão, devido ao estabelecimento de uma melhor irrigação do tecido, ocorrendo então diminuição da necrose e da fibrose neste sítio ${ }^{8}$. No presente estudo, este achado não ocorreu, visto que praticamente todos os animais estudados apresentaram necrose ou fibrose no ovário enxertado. Pôdese notar em todos os grupo, presença de reação inflamatória extensa em todo o omento maior, provavelmente devido também ao próprio trauma cirúrgico, que talvez tivesse obtido maior êxito se realizado através de incisão menor, ocasionando menor reação inflamatória no abdome como um todo; associado a trauma, tem-se ainda a ineficiente imunossupressão, que não foi capaz de controlar esta reação imunológica.

Portanto, o enxerto de ovário íntegro realizado em omento maior de ratas, independente do uso ou não da Ciclosporina A, não mostrou-se viável de acordo com o método utilizado. A dose adequada de Ciclosporina, o uso de substâncias anti-inflamatórias e o enxerto do ovário fragmentado, seriam alternativas interessantes a serem pesquisadas para melhorar os índices apresentados neste trabalho.

\section{Conclusão}

O enxerto de ovário íntegro realizado em omento maior de ratas, nesta amostra, independente do uso da Ciclosporina, não se mostrou viável.

\section{Referências}

1. Stiff PJ, Bayer R, Kerger C, e col. High-dose chemotherapy with autologous transplantation for persistent/relapsed ovarian cancer: a multivariate analysis of survival for 100 consecutively treated patients. J Clin Oncol. 1997;15:1309-17.

2. Dissen GA, Larat HE, Fahrenbach WH, Costa ME, Ojeda SR. Immature rat ovaries become revascularized rapidly after autotransplantation and show gonadotropindependent increase in angiogenic factor gene expression. Endocrinology. 1994;134: 1146-54.0

3. Wood C. Ovarian transplantation. Br J Obstet Gynaecol. 1982;89: 597-7.

4. Matera JM, Barnabe VH, Gambarini ML, Geurra JL. Estudo experimental do enxerto autólogo de ovário em cadelas submetidas à ovariectomia e ovariosalpingohisterectomia. Acta Cir Bras. 1998;13: 44-52.

5. Salle B, Lornage J, Franck M, Isoard L, Rudigoz RC, Guerin JF. Freezing, thawing, and autograft of ovarian fragments in sheep: preliminary experiments and histologic assessment. Fert Ster. 1998;70: 124-8.

6. Brito NMB, Silva PRF, Fernandes EO, Brito RB. Estudo microscópico de ovário autotransplantado em ratas submetidas à ooforectomia. Rev Paul Med. 2002;16: 28-31.

7. Caldwell BV, Pawling RS, Wright PA. Restablishment of ovarian periodicity after transplantation to the syrian hamster cheek pouch. Proc Soc Exp Biol Med. 1966;123(2):551-3.

8. Alberti LR, Vasconcellos LS, Barbosa JF, Petroianu A. Implante autólogo ovariano no omento maior - Estudo experimental. Rev Bras Ginecol Obstet. 2002;24(3):187-92.

9. Rodrigues AZ, Nigro AJT, Paiva ER, Sementilli A, Tavares NM. Estudo comparativo da viabilidade de fragmento de tecido esplênico autólogo implantado no omento maior ou na tela sub-cutânea de ratas. Acta Cir Bras. 1991;6(2):64-7. 
10. Corleta HE, Corleta O, Capp E, Edelweiss MI. Subcutaneous autologous ovarian transplantation in Wistar rat maintains hormone secretion. Fert. Ster. 1998;70:16-9.

11. Carramaschi FR, Landman G, Corsi RCC, Vana LMP, Ferreira MC. Rat allotransplantation of epigastric microsurgical flaps: a study of rejection and the imunossupressive effect of cyclosporin A. Rev Hosp Clin Fac Med Univ Säo Paulo.2000;55(1):21-8.

12. Brito NMB, Kulay-Júnior L, Simões MJ, Lameira AO, Lamarão LG, Damous SHB. Aspectos Morfológicos e Morfométricos do Colo Uterino de Ratas Ooforectomizadas após Aplicação de Óleo de Copaíba.
Rev Bras Ginecol Obstet. 2000;22 (8):489-93.

13. Bowman AR; Sass DA; Marshall I; Ma YF; Liang H; Jee WS; Epstein S. Raloxifene analog (LY117018 HCL) ameliorates cyclosporin A-induced osteopenia in oophorectomized rats. J Bone Miner Res. 1996;11(8):1191-8.

14. Carmona F; Balasch J; González-Merlo J. Ovarian function, tubal viability and pregnancy after tuboovarian transplantation in the rabbit. Hum Reprod. 1993;8(6):929-31.

15. Esquifino AI; Moreno ML; Agrasal C; Villanúa MA. Effects of cyclosporine on ovarian function in shamoperated and pituitary-grafted young female rats. Proc Soc Exp Biol Med. 1995;208(4):397-403.
Correspondência:

Nara Macedo Botelho Brito

Tv. Apinagés, 630 - apto 201 - Batista Campos - Belém - PA.

CEP: 66033-170

Tel.: (91) 223-3607 / 9981-6321

E-mail:narabrito@amazon.com.br
Conflito de interesse: nenhum Fonte de financiamento: Pró-Reitoria de Pesquisa e Pós-Graduação

Recebimento: 18/11/2004

Revisão: $14 / 12 / 2004$

Aprovação: 17/01/2005

\section{Como citar este artigo:}

Brito NMB, Torres IO, Silveira EL, Santos LLT. Estudo da viabilidade do enxerto de ovário na bolsa omental de ratos utilizando Ciclosporina A. Acta Cir Bras [serial online] 2005 Mar-Abr; 20(2). Disponível em URL: http://www.scielo.br/acb 